be attributed the difficulty which Dr. Boas encountered in studying our material in comparison with his own from that region. Washington, May 30.

An American dialect society.

Referring to the letter by R. B. in Science of May 20 , it is certainly possible to establish an American dialect society. Yet I believe it much the better way to have the work undertaken by the American philological association than to form a new society. In my opinion, the advance of philological science will be much more readily promoted by a combination of the various societies now existing than by the formation of others. Philology would be the gainer if the Oriental and Modern language associations could be united with the American under one control. The success of the American association for the advancement of science should teach that in union there is strength, and that a large society attracts not only more attention from the public, but brings to its meetings a much larger proportion, as I believe, of its own members. The work of a dialect society is so largely local in its character that it can best be done by a large number of persons. That such a work should be done needs little proof. The principal question is, By whom shall it be done?

S. C. Derby.

Columbus, O., May 24 .

\section{The causation of consumption.}

Within the last few years the attention of the medical profession has been more than ever turned to the consideration of the cause or causes of pulmonary consumption. The renewed interest in the etiology of this disease is owing to the discovery of the bacillus tuberculosis. This important event gave origin to two theories; the one holding that the only cause of consumption was the bacillus tuberculosis, and the other that the disease but furnished a nidus for the bacillus, and that hence its presence was not a cause, but an effect. This difference of opinion among physicians has not materially altered even to the present day; and, while the factors of the problem which give rise to this difference of opinion remain unsolved, it is savoring of dogmatism to say that it is decided that so and so is the cause of consumption.

As we proceed further in our investigation of the causation of consumption, we find the adherents of one theory placing great stress upon heredity, and, on the other hand, men of the highest authority and standing in the medical profession giving it as their opinion that there is no direct heredity other than that the child of phthisical parents starts in life with a small stock of vitality, and is thus rendered more liable to the invasion and the destructive influences of any and all diseases.

At the present state of the inquiry it seems some. what too hasty to say just what the cause of pulmonary consumption may be; but it certainly appears that this cause is compound, being made up of at least three several elements: to wit, -

$1^{\circ}$. The feeble vitality or resisting power with which the given organism enters upon life.

$2^{\circ}(a)$. The action of an environment upon this organism detrimental to the maintenance of a good general health; or (b) in some cases the existence of a state of debility after an acute disease. $3^{\circ}$. The organism thus influenced being exposed to the action of the bacillus tuberculosis.

The bacillus tuberculosis is so widely disseminated in the air we breathe, and distributed in the food we eat, that, were it the only or the main cause of consumption, we might expect the extermination of the human race within a few years.

We may plant corn upon unsuitable soil, and there will be no growth ; we may plant it upon prepared soil and exclude the sunlight, heat, and moisture, and there will be no growth; and so the bacillus tuberculosis is deposited in the lungs of every one of us nearly every day, and yet it takes no hold upon the majority, because either the system is refractory to it, or our environment is such that it cannot develop.

JAMES P. MARSH.

Green Island, N.Y., May 30.

The equivalence in time of American marine and intracontinental tertiaries.

In a paper published in the May number of the American journal of science, Dr. C. A. White discusses the possibilities of correlating in detail the North American intracontinental and marine tertiaries, and refers to the identification by Prof. L. F. Ward of four species of plants from the tertiaries of the Mexican gulf border, with those found in the Laramie group. I am unable to refer to the report of Professor Ward, which has not yet reached this coast, and am therefore unaware whether the plants referred to are from the country east or west of the Mississippi River; but I would take this occasion to call attention again to the opportunities afforded for the establishment of such correlations, in northwestern Louisiana, south-western Arkansas, and the adjacent portions of Texas and the Indian Territory, where the marine formations, still recognizable in detail by their characteristic shells, are indefinitely split up, both horizontally and vertically, into a maze of marine outliers and fresh and brackish water deposits, of the equivalence and continuity of which there can be no possible question. Among these, certain fresh-water deposits on the upper Red River in Louisiana are extremely rich in well-preserved leaves and fruits, of which a collection (deposited at the University of Mississippi at Oxford) was made by me in 1869 . Among my publications setting forth these facts, I have, in a paper read at the Indianapolis meeting of the American association for the advancement of science in 1871 , pointedly alluded to the probable original continuity of this 'Mansfield group' of Louisiana with intracontinental tertiaries, and the further probability, that, by means of remaining outliers, at least a chronological scale for parallelizing these formations might be established along the shallow connecting trough outlined by the cretaceous shore-lines. While my supposition that the cross-timbers of Texas were also of tertiary age, has since been disproved, I am not aware that any exhaustive examination of the region lying between the Red and Arkansas rivers in the Indian Territory has been made; yet it is there that such direct connection must have existed, if at all within tertiary times. The striking increase of the lignitiferous facies toward the north-western border of the Gulf tertiary area, culminating in the appearance of bands of fresh-water limestone at Mansfield and north-westward; the fan-like expansion, in Arkansas and Louisiana, of the older por- 
tion of the narrow bands formed by the marine stages in Mississippi and Alabama; with a manifest north-westward trend of such deposits as are continuously traceable in north-western Louisiana, while the later stages are abruptly deflected to the south-west, - all points to a rapidly progressing elevation of the axial cretaceous trough, that may, or may not, have completely separated the interior from the Gulf waters before the beginning of the tertiary period. In any event, the region referred to appears to me to be a critical one, deserving of exhaustive examination in advance of many others that offer only a subordinate interest in cornparison to the problem of the correlation of the intracontinental and the marine tertiary.

E. W. HILGARD.

Berkeley, Cal., May 17.

\section{The pelvis of the dugong.}

As far as I am aware, the pelvis of Halicore australis has never been properly described or figured.

Last fall I had the opportunity of examining, here at my father's establishment, six ligamentary skeletons, embracing both sexes, of this animal. A few hasty notes made at the time, and a section of vertebrae, including the pelvis (in which, unfortunately, the ischia have been torn asunder and separated from their haemapophysis), is all the material I can lay hands on, now that I have time to look the matter up: cousequently my drawing and description cannot include a few points that I would wish.

In all six cases the fourth post-dorsal vertebra is the first sacral. The ilia are connected to the distal

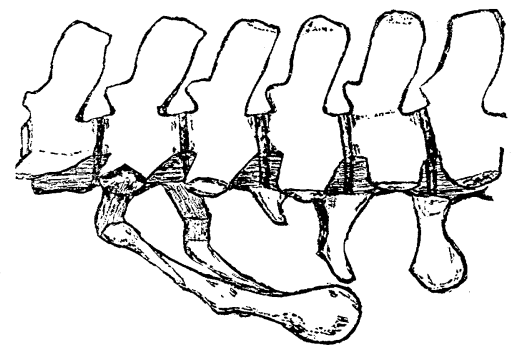

ends of its diapophyses by short ligaments. The ends of these diapophyses are greatly swollen dorsoventrally, their vertical diameter being thirty-three millimetres, whereas the preceding one measures but ten millimetres. The diapophyses of the two succeeding (sacral) vertebrae are also decidedly thicker at the ends than is the case in either the last lumbar or the succeeding caudals. Anchylosed to the ilia are the ischia lying in the same line, and showing their junction by a prominent swelling in the mass of the bone.

The distal ends of the ilia were connected with each other by a short ligament, and separated from the apex of the haemapophysis of the second succeeding vertebrae by but a few millimetres, connected to it either by a ligament or muscle, but which it is now too late to determine.

The ilium is 109 millimetres in length ; the ischium, 102 ; the transverse diameter of its distal end, 46 ; the anterior-posterior length of the symphysis ischia, 34 .

The first haemapophysis consists of two straight V-shaped bones $30^{\prime \prime}$ millimetres long, 29 millimetres apart at bases, with points diverging to a distance of 51 millimetres. The next, to which the ischia join, has its two parts curving inward, leaving an oval opening, the extremities not quite meeting, and ligamentously connected. The succeeding haemapophyses have their ends anchylosed, and are V-shaped.

The point that I especially wish to emphasize is, that the pelvis is not vertical to the axis of the vertebral column, but lies at practically the same angle as. ordinarily obtains in the mammalia.

In the six specimens examined, two had nineteen thoracic vertebrae, while four had but eighteen. All had three lumbar vertebrae. The thoracic are generally stated as being nineteen in number: with these this was the exception.

It is further to be noticed that the dugong appears to be an exception to the rule that when the number of thoracic vertebrae is increased or diminished there is a compensating diminution or increase in the number of lumbar vertebrae. Henry L. WARD.

Rochester, N.Y., May 24.

\section{A cretaceous river-bed.}

The springs at San Marcos, Hays county, Tex., where the San Marcos River rises full grown from the earth, with a steadiness of flow in marked contrast with the majority of Texas rivers, are, aside from their scientitic aspects, sufficiently interesting to have been a subject of popular speculation and newspaper discussion ever since the settlement of Texas. The theories that have been advanced are various, from the popular idea that it is sufficiently explained by the presence of a cave full of water under the hill, to the explanation proposed by an imaginative newspaper editor, that the water comes underground from the Rocky Mountains.

I have not felt it necessary to familiarize myself with the details of this discussion, since, although my conclusions may be to some extent old, the proof is certainly new; for the general principle upon which it is based has been but recently announced by $\mathrm{Mr}$. Robert T. Hill in the American journal of science for April (xxxiii. p. 29); namely, that there exists between the earlier cretaceous strata of Texas and the superimposed rocks a plane of 'non-conformity by erosion,' indicating an interval of emergence between the two periods of cretaceous rock formation.

The strata in the vicinity of San Marcos not only furnish a striking proof of the truth of this principle, but they become a key to whatever is mysterious in the origin of the San Marcos River.

The accompanying section roughly represents the rocks exposed by the San Marcos at its source.

No better stratigraphical landmark than the stratum $b b$, the Exogyra arietina marl, could be desired. The exposures at San Marcos are typical ones, containing an unusually large proportion of perfect bivalve specimens of Exogyra arietina R., besides the usual smaller quantity of Gryphara Pitcheri, etc. Its exposures are from fifty to one hundred feet above the river-level, and, in connection with the Ostrea carinata bed below, furnish conclusive proof that these rocks are of the Washita division of the earlier or Texas cretaceous; lacking, however, the uppermost members of that series.

In the little valleys back of the portion of the section marked $a a$, I found a conglomerate composed of fragments of the hard earlier limestones and 